\title{
SASO: Sistema de Apoio à Saúde Ocupacional
}

\author{
Isabela F. França ${ }^{1}$, Antônio E. Pereira, Melyssa M. G. Silva, \\ Bruna M. O. S. Cordeiro, Iwens. G. Sene Junior, Renato F. Bulcão-Neto \\ ${ }^{1}$ Instituto de Informática - Universidade Federal de Goiás (UFG) \\ Caixa Postal 74001-970 - Goiânia - GO - Brasil \\ isabela_franca@discente.ufg.br, brunacordeirodinf.ufg.br \\ iwens@ufg.br, rbulcao@ufg.br
}

\begin{abstract}
The economically active population comes on average about a third of their time in the workplace and health problems caused there to result in an economic loss for most countries. Whereas air quality is one of the main public health problems, it is essential that there is constant monitoring in the workplace. Thus, this article aims to present the Occupational Health Support System (SASO) consisting of an IoT solution that monitors, in real-time, the air quality in indoor and climate-controlled environments, providing the information collected in a dashboard for the final user.
\end{abstract}

Resumo. A população economicamente ativa passa, em média, cerca de um terço de seu tempo no local de trabalho e os problemas de saúde aí causados resultam em perdas econômicas para a maioria dos países. Considerando que a qualidade do ar é um dos principais problemas de saúde pública, é fundamental que haja um monitoramento constante nos locais de trabalho. Assim, este artigo tem como objetivo apresentar o Sistema de Apoio à Saúde Ocupacional (SASO) que consiste em uma solução IoT que monitora, em tempo real, a qualidade do ar em ambientes internos e climatizados, disponibilizando as informações coletadas em um painel para o usuário final .

\section{Introdução}

De acordo com a OMS pessoas economicamente ativas passam em média cerca de um terço de seu tempo no local de trabalho e problemas de saúde relacionados ao trabalho resultam em uma perda econômica de 4-6\% do PIB para a maioria dos países. A saúde dos trabalhadores é um pré-requisito essencial para a renda familiar, produtividade e desenvolvimento econômico.

Existe uma consciência crescente da necessidade de aplicar medidas práticas no local de trabalho para reduzir doenças e acidentes de trabalho [Office et al. 2001]. O Ministério do Trabalho, através da NR $17^{1}$ que trata sobre ergonomia, estabelecer parâmetros que permitam a adaptação das condições de trabalho às características psicofisiológicas dos trabalhadores, de modo a proporcionar um máximo de conforto, segurança e desempenho eficiente. Os níveis dos parâmetros estabelecidos citados, ao qual deve-se estar atento, para ter condições de conforto adequadas, são de ruído, iluminação, ventilação, umidade e temperatura.

\footnotetext{
${ }^{1}$ Norma Regulamentadora $N^{\circ} 17$ - https://www.gov.br/trabalho/pt-br/inspecao/ seguranca-e-saude-no-trabalho/ctpp-nrs/normas-regulamentadoras-nrs
} 
A iluminação inadequada no ambiente de trabalho pode causar fadiga ocular, fadiga excessiva, ataque epilético, em casos de oscilações de luminosidade, operação errada dos equipamentos de trabalho, ofuscamento, entre outros [Office et al. 2001]. O ruído por sua vez, causa efeitos como: problemas relacionados ao sono, problemas de desempenho cognitivo e aumento da pressão arterial [Marques et al. 2020]. O controle não efetivo de umidade, temperatura e ventilação pode causar aumento de contaminantes biológicos e não biológicos, gerando por consequência, o aumento de doenças [Wolkoff 2018]. Esses fatores influenciam a qualidade do ar interno e resultam na chamada Síndrome dos Edifícios Doentes (SED) [Teixeira et al. 2005].

A literatura apresenta cada vez mais soluções IoT que realizam o monitoramento da qualidade do ar em ambientes internos, isso tem ocorrido pois os sistemas convencionais baseados em estações de medição são caros e oferecem baixa granularidade de dados. A fim de fundamentar o estado da arte, uma pesquisa abrangente sobre as soluções IoT voltadas para o monitoramento da qualidade do ar é apresentada em [Mokrani et al. 2019].

Este trabalho faz parte de um projeto de pesquisa em iniciação científica em andamento, que tem o objetivo de desenvolver um Sistema de Apoio à Saúde Ocupacional (SASO). O sistema é composto por uma solução IoT para monitoramento da qualidade do ar em ambientes internos com a finalidade de apoiar a Diretoria de Atenção à Saúde do Servidor (DASS) da Universidade Federal de Goiás. Detalhes da construção da solução IoT estão descritos na seção 2 deste artigo. A seção 3 apresenta a etapa de planejamento e implementação do sistema e por fim, a seção 4 relata o estado atual da pesquisa.

\section{Solução IoT para monitoramento da qualidade do ar}

A visão da Internet of Things (IoT) consiste hoje em conectar as coisas de modo que seja possível obter informações de objetos simples [Ashton et al. 2009]. Pensando nisso, desenvolveu-se uma solução IoT composta por sensores que realiza o monitoramento da qualidade do ar em ambientes internos. A solução tem a finalidade de coletar as informações que serão necessárias para a implementação do SASO. Na Figura 1, é possível visualizar a case impressa em 3D e os componentes utilizados.

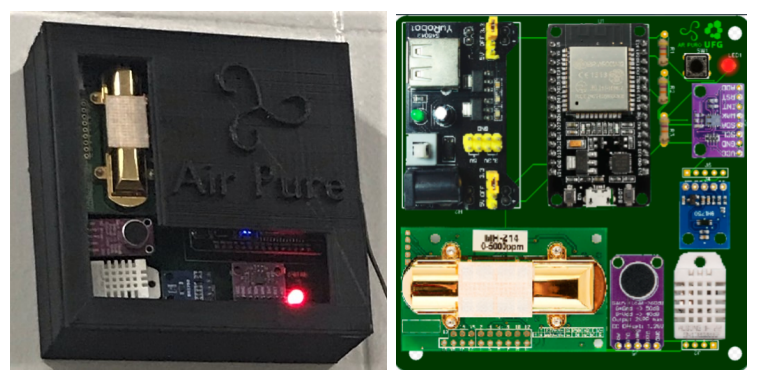

Figura 1. Protótipo desenvolvido

O protótipo tem a finalidade de monitorar fatores de: umidade relativa, temperatura, dióxido de carbono $\left(\mathrm{CO}_{2}\right)$, Compostos Orgânicos Voláteis Totais (COVT), iluminância e ruído. Os dados são coletados por sensores específicos a cada 20 segundos. A Tabela 1 apresenta os fatores monitorados por cada sensor utilizado, e os valores limites, máximos e mínimos, conforme legislações seguidas. 
Tabela 1. Fatores Monitorados pelo dispositivo

\begin{tabular}{llccl}
\hline Sensor & Fator & Máximo & Mínimo & Legislação \\
\hline DHT22 & Umidade Relativa & $65 \%$ & $35 \%$ & Anvisa - No 09/2003 \\
DHT22 & Temperatura & $26^{\circ} \mathrm{C}$ & $20^{\circ} \mathrm{C}$ & Anvisa - N $09 / 2003$ \\
MH-Z14A & $\mathrm{CO}_{2}$ & $1000 \mathrm{ppm}$ & $400 \mathrm{ppm}$ & Anvisa - N $09 / 2003$ \\
CCS811 & $\mathrm{COVT}_{\text {N }}$ & $500 \mu \mathrm{g} / \mathrm{m}^{3}$ & - & Diretrizes da OMS \\
BH1750 & Iluminância & $1000 \mathrm{lux}$ & $500 \mathrm{lux}$ & NBR-5413 \\
MAX9814 & Ruído & $65 \mathrm{~dB}$ & $30 \mathrm{~dB}$ & NBR-1052 \\
\hline
\end{tabular}

O hardware foi modelado em uma placa de circuito impresso e o módulo NodeMCU ESP32S foi utilizado para processamento e comunicação com os sensores apresentados na Tabela1. A ESP332S trata-se de um chip com baixo consumo de energia desenvolvido para dispositivos móveis, eletrônicos vestíveis e aplicações IoT. Além disso, também possui capacidade de comunicação via Wi-Fi e dual-mode Bluetooth.

O código fonte desenvolvido possui otimizações para menor consumo de energia e atualização automática da rede $W i$-Fi. Os dados recebidos dos sensores são processados, analisados, armazenados em um banco de dados e exibidos ao usuário final por meio de uma aplicação web.

\section{Planejamento e implementação do sistema SASO}

Durante a fase de levantamento de requisitos para implementação de sistema, identificouse a necessidade de possuir: indicadores apresentando os valores atuais; visualização gráfica dos dados coletados ao longo do dia; identificação da localização do dispositivo; consulta aos dados durante um período de data especificado, e; um sistema de notificação via $e$-mail quando os fatores monitorados assumirem valores fora do permitido em legislações. A Figura 2 apresenta a tela inicial do SASO.

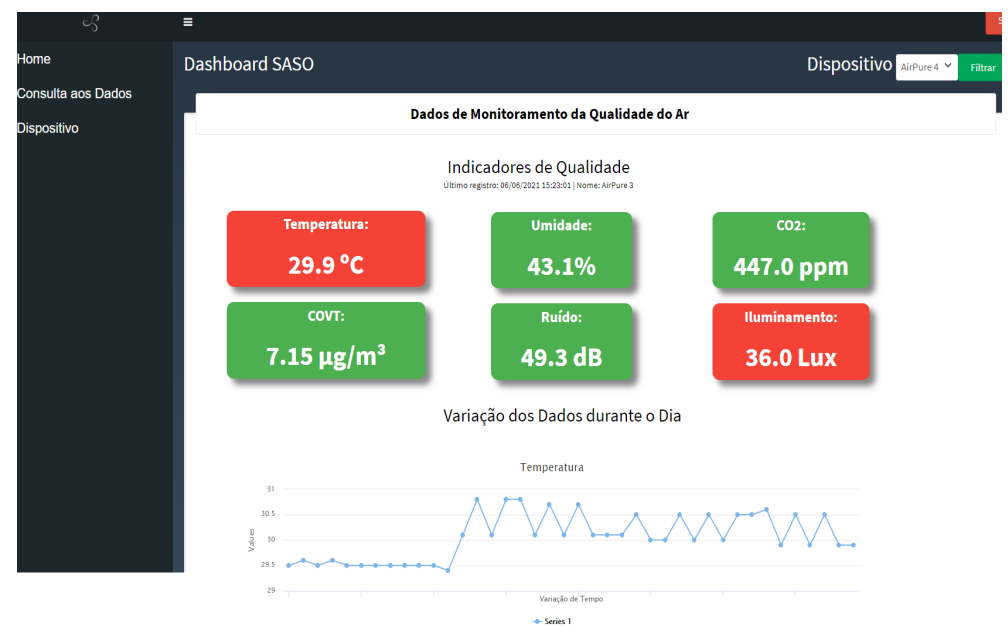

Figura 2. Monitoramento da Qualidade do Ar

O sistema SASO é composto por um dashboard acessado por meio de usuário e senha, apresentado na Figura 2, onde é possível visualizar indicadores contendo os 
últimos valores lidos pelos sensores em formato numérico e gráficos de todos os fatores com dados coletados durante todo o dia.

Uma escala de cores indica se os valores estão dentro do estabelecido, conforme os valores de máximo e mínimo contidos na Tabela 1 , onde o verde simboliza os valores dentro do permitido, o amarelo simboliza que o valor está se aproximando do limite, o vermelho indica que o valor está fora do limite.

O menu lateral é composto por duas opções principais: consulta aos dados, onde é possível filtrar um período específico para visualização gráfica dos dados coletados, e dispositivo, onde é possível atualizar as preferências quanto às notificações e visualizar a localização do dispositivo. As notificações são personalizadas na própria interface do sistema, é possível escolher quais parâmetros deseja ser notificado. Assim que os valores ultrapassarem os limites, um e-mail é enviado automaticamente com todas as informações.

\section{Estado atual das pesquisas}

O trabalho apresentado neste artigo está em fase de finalização. Atualmente o dispositivo está instalado em um laboratório da Escola de Veterinária e Zootecnia da Universidade Federal de Goiás e possui como usuários professores, coordenadores e funcionários do local. Acredita-se que os dados coletados poderão ser úteis para tomada de decisão, fornecendo auxílio para uma análise mais pontual, da higiene ocupacional realizada pela DASS.

A bolsista vinculada ao projeto finalizou a montagem do dispositivo físico, a construção da aplicação web e a instalação do mesmo. Como trabalhos futuros, pretendese realizar uma avaliação qualitativa sobre a usabilidade do sistema, bem como avaliar possíveis melhorias no protótipo, quanto aos sensores utilizados e os tipos de dados coletados, como também uma análise em relação as funcionalidades oferecidas pela aplicação web disponibilizada aos usuários.

\section{Referências}

Ashton, K. et al. (2009). That 'internet of things' thing. RFID journal, 22(7):97-114.

Marques, G. et al. (2020). Noise exposure in residential buildings: An internet of things approach for enhanced acoustic comfort and occupational health. In 15th Iberian Conference on Information Systems and Technologies (CISTI), pages 1-6. IEEE.

Mokrani, H. et al. (2019). Air quality monitoring using iot: A survey. In IEEE International Conference on Smart Internet of Things (SmartIoT), pages 127-134.

Office, I. L. et al. (2001). Pontos de verificação ergonômica, soluções práticas e de fácil aplicação para melhorar a segurança, a saúde e as condições de trabalho, preparado e traduzido pela fundacentro. São Paulo.

Teixeira, D. B. et al. (2005). Síndrome dos edifícios doentes em recintos com ventilação e climatização artificiais: Revisão de literatura. In VIII Congresso Brasileiro de Defesa do Meio Ambiente, pages 1-11, Rio de Janeiro, RJ, Brasil.

Wolkoff, P. (2018). Indoor air humidity, air quality, and health-an overview. International journal of hygiene and environmental health, 221(3):376-390. 